\title{
Computational fluid dynamics for non-experts: Development of a user-friendly CFD simulator (HNVR-SYS) for natural ventilation design applications
}

\author{
Rack-woo Kim ${ }^{a}$, Se-woon Hong ${ }^{b, c, *}$, Tomas Norton ${ }^{c}$, Thomas Amon ${ }^{\text {d,e }}$, \\ Ali Youssef ${ }^{c}$, Daniel Berckmans ${ }^{c, f}$, In-bok Lee ${ }^{a}$ \\ a Department of Rural Systems Engineering, Research Institute for Agriculture and Life Sciences, College of \\ Agriculture and Life Sciences, Seoul National University, 599, Gwanakno, Gwanakgu, Seoul, 08826, Republic of \\ Korea \\ ${ }^{\mathrm{b}}$ Department of Rural and Biosystems Engineering, College of Agriculture and Life Sciences, Chonnam National \\ University, 77 Yongbong-ro, Buk-gu, Gwangju, 61186, Republic of Korea \\ ${ }^{c}$ Division of Animal and Human Health Engineering, KU Leuven, Kasteelpark Arenberg 30, 3001 Leuven, Belgium \\ ${ }^{d}$ Leibniz Institute for Agricultural Engineering Potsdam-Bornim (ATB), Department of Engineering for Livestock \\ Management, Max-Eyth-Allee 100, 14469 Potsdam, Germany \\ ${ }^{\mathrm{e}}$ Institute of Animal Hygiene and Environmental Health, Department of Veterinary Medicine, Freie Universität \\ Berlin, Robert-von-Ostertag-Str. 7-13, 14163 Berlin, Germany \\ ${ }_{\mathrm{f}}^{\mathrm{f}}$ BioRICS NV, Technologielaan 3, 3001, Heverlee-Leuven, Belgium
}

\section{A R T I C L E I N F O}

Article history:

Received 16 January 2019

Received in revised form

28 February 2020

Accepted 4 March 2020

Keywords:

Automation

Computational fluid dynamics

Natural ventilation

OpenFOAM

Ventilation rate
Measuring the ventilation rate is crucial to ensuring the control of thermal comfort, energy saving, and emission of pollutants in greenhouses and animal houses. This is more difficult in naturally ventilated (NV) buildings because of the dynamic and complex air flow patterns caused by wind and buoyancy effects. In this study, a user-friendly computational fluid dynamics (CFD) simulator is developed to analyse internal airflow patterns and ventilation rates of NV buildings, with the initial focus on agricultural buildings. The userfriendly CFD automation program, developed using the freely available open-source OpenFOAM and ParaView visualization toolkit, is aimed at non-CFD experts to help them obtain practical CFD solutions quickly. Users simply input building and ventilating configurations, outdoor wind conditions, topographical conditions, and information regarding plants or animals through user-friendly graphical user interfaces. General CFD processes are automated, and the quality of each process is controlled. After executing the program, a three-dimensional interactive visualization module is used for post-processing. It can ensure the flexibility and manageability of the model by automating predeveloped procedures in a user-interactive manner, thereby reducing time and effort. This paper describes the development process of automation interfaces. 


\begin{tabular}{|c|c|c|c|}
\hline \multicolumn{2}{|c|}{ Nomenclature } & $r_{s}$ & Stomatal resistance of the leaf $\left(\mathrm{s} \mathrm{m}^{-1}\right)$ \\
\hline$A_{c}$ & Surface area of the animal $\left(\mathrm{m}^{2}\right)$ & $r_{t}$ & Total resistances on both sides of the leaf $\left(\mathrm{s} \mathrm{m}^{-1}\right)$ \\
\hline$A_{p}$ & Cross-sectional area projected in the direction of & $\mathrm{S}_{\varphi}$ & Source term for the time scalar \\
\hline & the airflow $\left(\mathrm{m}^{2}\right)$ & $\mathrm{S}_{\mathrm{T}}$ & $\begin{array}{l}\text { Source term for the sensible heat generation by } \\
\text { animals or plants }\left(\mathrm{K} \mathrm{s}^{-1}\right)\end{array}$ \\
\hline B & Size of inner box $(\mathrm{m})$ & $S_{U}$ & Source term for the kinematic pressure loss by \\
\hline $\mathrm{C}_{1}$ & Parameters related to viscous $\left(\mathrm{m}^{-2}\right)$ & $J_{U}$ & animals or plants $\left(\mathrm{m} \mathrm{s}^{-2}\right)$ \\
\hline $\mathrm{C}_{2}$ & Parameters related to inertial resistances $\left(\mathrm{m}^{-1}\right)$ & $\mathrm{T}$ & Temperature (K) \\
\hline$C_{d}$ & Drag coefficient & $\mathrm{T}_{\mathrm{ref}}$ & Reference temperature $(\mathrm{K})$ \\
\hline$C_{p}$ & Specific heats of air $\left(\mathrm{J} \mathrm{kg}^{-1} \mathrm{~K}^{-1}\right)$ & $\mathrm{T}_{\mathrm{a}}$ & Temperature of air $(\mathrm{K})$ \\
\hline$C_{p l}$ & Specific heats of leaves $\left(J \mathrm{~kg}^{-1} \mathrm{~K}^{-1}\right)$ & $\mathrm{T}_{\mathrm{avg}}$ & Average absolute temperature of the surface \\
\hline $\mathrm{C}_{\mu}$ & Dimensionless constant & & temperature and bulk temperature $(\mathrm{K})$ \\
\hline $\begin{array}{l}\mathrm{d} \\
D_{\max }\end{array}$ & $\begin{array}{l}\text { Characteristic dimension of the animal }(\mathrm{m}) \\
\text { Maximum saturation deficit }\end{array}$ & $\mathrm{T}_{\mathrm{bd}}$ & Temperature of body core $(\mathrm{K})$ \\
\hline$D_{s a} t$ & Saturation deficit of air & $\mathrm{T}_{\mathrm{c}}$ & Temperature of hair-coat surface $(K)$ \\
\hline$D_{t}$ & Diffusivity of the time scalar $\left(\mathrm{m}^{2} \mathrm{~s}^{-1}\right)$ & $\Delta \mathrm{T}$ & Mean difference between the surface temperature \\
\hline$E_{c}$ & Latent heat loss from the skin $\left(\mathrm{W} \mathrm{m}^{-2}\right)$ & & and bulk temperature $\left({ }^{\circ} \mathrm{C}\right)$ \\
\hline$E_{r}$ & Latent heat loss from the respiratory tract $\left(\mathrm{W} \mathrm{m}^{-2}\right)$ & $\mathrm{T}_{\mathrm{flr}}$ & Temperature of floor $(\mathrm{K})$ \\
\hline$F_{d}$ & Drag force acting on an animal $\left(\mathrm{kg} \mathrm{m} \mathrm{s}^{-2}\right)$ & $\mathrm{T}_{1}$ & Temperature of leaf $(\mathrm{K})$ \\
\hline G & Gravitational acceleration $\left(\mathrm{m} \mathrm{s}^{-2}\right)$ & $\mathrm{t}_{1}$ & Thickness of the leaf $(\mathrm{m})$ \\
\hline $\mathrm{h}$ & Crop height (m) & $\mathrm{T}_{\mathrm{mid}}$ & Average temperature between the skin and the \\
\hline $\mathrm{H}$ & Height (m) & & outer surface of hair-coat $(\mathrm{K})$ \\
\hline $\mathrm{H}_{\mathrm{a}}$ & Animal height $(\mathrm{m})$ & $\mathrm{T}_{\mathrm{m}}$ & Average temperature $\mathrm{K}$ between the ra \\
\hline$h_{g}$ & Geostrophic plane height of the ABL (m) & & $\begin{array}{l}\text { temperature of the enclosure } T_{r} \text { and the harr-coat } \\
\text { temperature } T_{C}(K)\end{array}$ \\
\hline $\mathrm{k}_{\mathrm{a}}$ & Thermal conductivity of air $\left(\mathrm{W} \mathrm{m}^{-1} \mathrm{~K}^{-1}\right)$ & & $\begin{array}{l}\text { temperature } I_{c}(K) \\
\text { Temperature of radiant enclosure }(K)\end{array}$ \\
\hline $\mathrm{K}_{\mathrm{c}}$ & Extinction coefficient & $\begin{array}{l}1_{\mathrm{r}} \\
\mathrm{T}_{\mathrm{s}}\end{array}$ & $\begin{array}{l}\text { lemperature of radiant enclosure }(\mathrm{K}) \\
\text { Temperature of skin }(\mathrm{K})\end{array}$ \\
\hline L & Characteristic length of the leaf $(\mathrm{m})$ & $\begin{array}{l}1 \mathrm{~s} \\
\mathrm{U}\end{array}$ & Velocity $\left(\mathrm{m} \mathrm{s}^{-1}\right)$ \\
\hline L & Length $(\mathrm{m})$ & $\nu$ & Kinematic viscosity $\left(\mathrm{m}^{2} \mathrm{~s}^{-1}\right)$ \\
\hline LAIV & Volumetric leaf area density $\left(\mathrm{m}^{2} \mathrm{~m}^{-3}\right)$ & $v_{T}$ & Kinematic turbulent viscosity $\left(\mathrm{m}^{2} \mathrm{~s}^{-1}\right)$ \\
\hline$l_{c}$ & Coat depth (m) & $v_{\mathrm{T}}$ & Velocity induced by the buoyancy effect \\
\hline$l_{c w}$ & Depth of wind penetration in the hair-coat $(\mathrm{m})$ & $\mathrm{Vz}$ & Volume of the animal zone in the building $\left(\mathrm{m}^{3}\right)$ \\
\hline M & Net rate of heat storage in metabolic reactions & $\mathrm{W}$ & Width $(\mathrm{m})$ \\
\hline $\mathrm{n}_{\mathrm{a}}$ & Number of animals in the building & $w_{a}$ & Humidity of air \\
\hline $\mathrm{N}_{\mathrm{u}}$ & $\begin{array}{l}\text { Nusselt number } \\
\text { Kinem }\end{array}$ & $w_{1}$ & Humidity of leaf \\
\hline P & Kinematic pressure $\left(\mathrm{m}^{2} \mathrm{~s}^{-2}\right)$ & $\beta$ & Thermal expansion coefficient $\left(\mathrm{K}^{-1}\right)$ \\
\hline$P_{c}$ & Coat penetration parameter $\left(\mathrm{m}^{-1}\right)$ & $\varepsilon$ & Emissivity \\
\hline$P_{\text {sat }}$ & Saturation pressure of air $(\mathrm{Pa})$ & $\kappa_{\text {eff }}$ & Effective thermal diffusivity $\left(\mathrm{m}^{2} \mathrm{~s}^{-1}\right)$ \\
\hline एa & the air $\left(\mathrm{W} \mathrm{m}^{-2}\right)$ & $\Lambda$ & Latitude of the position $\left({ }^{\circ}\right)$ \\
\hline$Q_{c}$ & Heat losses from the skin to the hair-coat surface & $\begin{array}{l}\Lambda \\
\mu_{\mathrm{t}} / \mu\end{array}$ & $\begin{array}{l}\text { Latent heat of water evaporation }\left(\mathrm{J} \mathrm{kg}^{-1}\right) \\
\text { Turbulent viscosity ratio }\end{array}$ \\
\hline$Q_{f r}$ & Heat losses from the skin to the floor $\left(\mathrm{W} \mathrm{m}^{-2}\right)$ & $\rho$ & Density of the air $\left(\mathrm{kg} \mathrm{m}^{-3}\right)$ \\
\hline$Q^{r}$ & Radiative heat loss from the hair-coat surface to & $\rho C_{p}$ & Volumetric specific heat of air $\left(\mathrm{J} \mathrm{m}^{-3} \mathrm{~K}^{-1}\right)$ \\
\hline & the air $\left(\mathrm{W} \mathrm{m}^{-2}\right)$ & $\rho l$ & Density of the leaves $\left(\mathrm{kg} \mathrm{m}^{-3}\right)$ \\
\hline$Q_{t}$ & Heat losses from the body core to the skin $\left(\mathrm{W} \mathrm{m}^{-2}\right)$ & $\sigma$ & Stefan-Boltzmann constant $\left(\mathrm{W} \mathrm{m}^{-2} \mathrm{~K}^{-4}\right)$ \\
\hline $\mathrm{R}$ & Proportion of the animal's trunk exposed to the air & $\varphi$ & Time scalar (s) \\
\hline $\mathrm{R}_{\mathrm{d}}$ & Radius of computational domain (m) & $\Omega$ & Angular velocity of the Earth's rotation ( $\mathrm{rad} \mathrm{s}^{-1}$ ) \\
\hline$R(z)$ & Solar radiation at height $\mathrm{z}\left(\mathrm{W} \mathrm{m}^{-2}\right)$ & ABL & Atmospheric Boundary Layer \\
\hline$r_{a}$ & Aerodynamic resistance of leaf $\left(\mathrm{s} \mathrm{m}^{-1}\right)$ & BBSFA & buoyant Boussinesq Simple Foam AM \\
\hline$r_{b}$ & Thermal resistance of the boundary layer on the & $\begin{array}{l}\text { BBSFP } \\
\text { DEM }\end{array}$ & buoyant Boussine sq Simple Foam PM \\
\hline & hair-coat surface $\left(\mathrm{m}^{2} \mathrm{~K} \mathrm{~W}^{-1}\right)$ & GUI & Graphical User Interfaces \\
\hline$r_{b t}$ & Thermal resistance of body tissue $\left(\mathrm{m}^{2} \mathrm{~K} \mathrm{~W}^{-1}\right)$ & LMA & Local Mean Age \\
\hline$R_{c}$ & Solar radiation absorbed by the leaf at the Height & LMR & Local Mean Residual Lifetime \\
\hline & $\begin{array}{l}\text { of } \mathrm{z}_{\mathrm{c}}\left(\mathrm{W} \mathrm{m} \mathrm{m}^{-3}\right) \\
\text { Thermal resistance of hair-coat }\left(\mathrm{m}^{2} \mathrm{~K} \mathrm{U}\right.\end{array}$ & low $\operatorname{Re}$ & Low Reynolds Number \\
\hline$r_{f i r}$ & Thermal resistance of floor $\left(\mathrm{m}^{2} \mathrm{~K} \mathrm{~W}^{-1}\right)$ & $\mathrm{NV}$ & Naturally Ventilated \\
\hline$R_{\text {net }}$ & Net solar radiation at the top of the crop & pvPyth & n ParaView Python Script \\
\hline$r_{r}$ & Radiative resistance of the boundary laye & RANS & Reynolds-Averaged Navier-Stokes \\
\hline & hair-coat surface $\left(\mathrm{m}^{2} \mathrm{~K} \mathrm{~W}^{-1}\right)$ & RNG & Renormalization Group ory \\
\hline
\end{tabular}




\section{Introduction}

With the rapidly increasing global population, food security demands safer and more food production from limited resources, with less environmental impact (EuropeanCommission, 2008). Natural ventilation is important for indoor livestock and plant production systems, as it allows the indoor climate to be managed with minimal energy. For this reason, natural ventilation has been studied over the last two decades (Bjerg, Norton, et al., 2013; Bournet \& Boulard, 2010; I.; Lee, 1998; I.; Lee, Sase, Okushima, Ikeguchi, \& Park, 2002; I.; Lee \& Short, 2000; I.; Lee \& Short, 2001; I.; Lee, Short, Sase, \& Lee, 2000; I.; Lee, Short, Sase, Okushima, \& Qiu, 2000).

The estimation of ventilation rates has always been a fundamental requirement in assessing the ventilation capacity of naturally ventilated (NV) buildings and has resulted in aerial emissions. However, as indoor agricultural systems are enlarging to take advantage of economies of scale, it is more challenging to maintain proper indoor air flows against unpredictable weather conditions, especially in terms of wind speed and direction (Kacira et al., 2004). Uncertain ventilation rates reduce the quality of indoor environment and cause uncontrolled emissions of air pollutants to the neighborhood (Behera, Sharma, Aneja, \& Balasubramanian, 2013; Hong, Lee, Hwang, Seo, Bitog, Kwon, Song, Moon, Kim, \& Ko, 2011; Hong, Lee, Hwang, Seo, Bitog, Kwon, Song, Moon, Kim, Ko, et al., 2011; Skjøth \& Geels, 2013; Takai et al., 2013).

Many methods have been developed to measure the ventilation rate of NV structures. Direct measurements use a range of anemometers but are primarily available for a limited number of point measurements over wide ventilation openings (Buggenhout, Ozcan, Vranken, Van Malcot, \& Berckmans, 2007). Indirect measurements using the tracer gas method and energy balance theory are being widely used, but the imperfect mixing of indoor air and microclimate result in inaccurate results (Ozcan \& Berckmans, 2010; Wang, 1998). Such measurement techniques are still being actively used despite their insufficient accuracy ( $25 \%$ errors on average) or inconvenience owing to bulky equipment (Buggenhout et al., 2007). Therefore, there is an increasing need for more accurate and convenient ventilation rate determination using numerical methods.

Computational fluid dynamics (CFD) simulation has been used to predict the complicated mechanisms of natural ventilation because of its advantage in predicting complex air flow patterns (Hong et al., 2017; Hong et al., 2008; I.; Lee et al., 2013; S.; Lee, Lee, \& Kim, 2018; Norton, Sun, Grant; Fallon, \& Dodd, 2007). While CFD simulations have been used in many different ventilation analyses, their results vary vastly in accuracy according to the researchers' skills and abilities. A modeller's skill in mesh design and problem understanding affect the final results significantly (Norton, Sun, Grant, Fallon, \& Dodd, 2007), as the airflows are driven by the complexity of the building configuration and local terrain. Moreover, CFD simulations are, to some extent, sensitive to the application for which the simulations are developed. In addition, if some changes in building shapes or ventilation configurations are required, the CFD model requires a re-design of mesh and geometry as a preprocessing, and a completely new simulation should be performed to adapt to those changes. Hence, CFD simulation requires relatively heavy workloads, which only CFD experts can manage; consequently, it is used primarily for research purposes rather than for practical use (Ai \& Mak, 2014; Wakes, Maegli, Dickinson, \& Hilton, 2010). CFD tools should, however, be made accessible to non-experts, such as farmers or agricultural building advisors/developers, to enable better building design in the agricultural industry.

This paper presents the development of a user-friendly CFD software that allows the practical use of the CFD technique in agricultural NV building design for non-experts. The ultimate goal is to develop an easy-to-use CFD simulator that automates all general pre-, main-, post-processing of CFD procedures for nonprofessional CFD users who wish to test their agricultural buildings by themselves (Hong, Exadaktylos, \& Berckmans, 2014). The CFD calculation included in the software enables the natural ventilation flows that are winddriven and buoyancy-driven and includes the effects of animals or plants on indoor thermal imbalance, thus resulting in airflows and the effect of terrain around the target building.

\section{HNVR-SYS: general aspects}

This study developed a handy natural-ventilation-rate (HNVR) calculator, named "simulate yourself (SYS)." The HNVR-SYS is an application program to automate the pre-, main-, and postprocesses of CFD simulations and to analyse the ventilation performance of NV agricultural buildings. Figure 1 presents the framework of the SYS tool. It consists of graphical user interfaces (GUIs) that handle open-source OpenFOAM CFD packages (Open Field Operation and Manipulation, ver. 2.1, OpenFOAM Foundation) and the ParaView (v. 3.12, Kitware) visualisation toolkit (VTK) libraries, which were used for CFD simulations and visualisation, respectively. OpenFOAM and ParaView VTK were selected for this study because they are free and open-source software that enables spin-off program applications to be produced. The OpenFOAM was available on the Linux operating system, but the original codes and new solvers developed in this study were cross-compiled to be operated on the Windows system that is more user-friendly.

The automation routines were developed using Microsoft Visual Basic (VB). It provides the GUIs for users to enter the input data and control options, manage CFD calculations, and return the simulation results. The simulated results are displayed by a three-dimensional interactive visualisation that is realised by the VTK libraries and controlled by the ParaView 


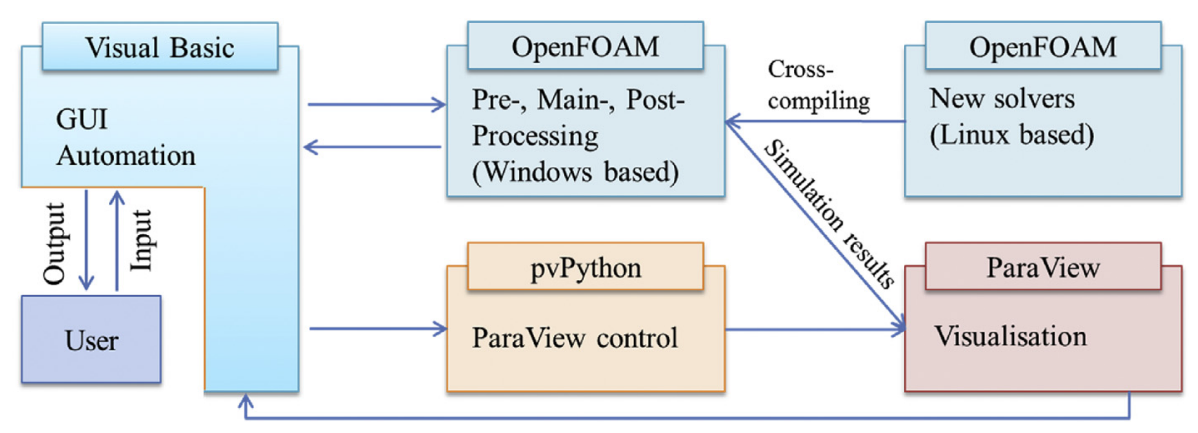

Fig. 1 - Framework of the CFD automation processes.

Python script (pvPython). Parallel computing solutions are also available for scientific purposes.

\section{Materials and methods}

This section describes the details of the CFD simulation and information regarding the automation processes. When users provide information upon a building structure, terrain, plants or animals, wind conditions, and simulation conditions, the program executes the scripted routines described in this section.

\subsection{OpenFOAM CFD}

OpenFOAM is a $\mathrm{C}++$-based open-source CFD package developed on the Linux platform. It is distributed under the GNU General Public Licence by the OpenFOAM Foundation, allowing for free use, modification, and redistribution. The package includes preprocessing utilities for mesh generation and modification, parallel processing utilities for data decomposition and reconstruction, and main solvers for incompressible, compressible, and buoyancy flows. In this study, OpenFOAM 2.1.x was used and cross-compiled using the MinGW-w64 cross-compiler and source code patch supported by Symscape (http://www.symscape.com) on Manjaro Linux (ver. 0.8.10).

The basic structure for an OpenFOAM case is a file-folder system. The OpenFOAM case consists of several files that contain all simulation data such as mesh information, simulation configuration, and computed results. Its proper handling enables the automation of CFD processes.

\subsection{Meshing strategy}

Meshing was comprised of four steps as described in (Hong et al., 2017) using SnappyHexMesh utility (Fig. 2). First, the building structure and terrain surfaces were modelled as STL (stereolithography) files (Fig. 3). The second step was to create an initial computational domain that surrounds the building and terrain surfaces and create an initial background mesh on the domain. The third step was to split the initial mesh into a finer mesh using the "snappyHexMesh" utility of the OpenFOAM. The final step was to improve the mesh quality for accurate simulation results. a)

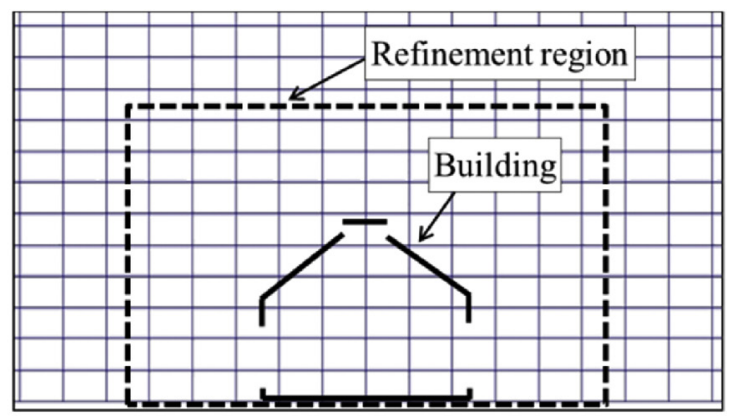

b)

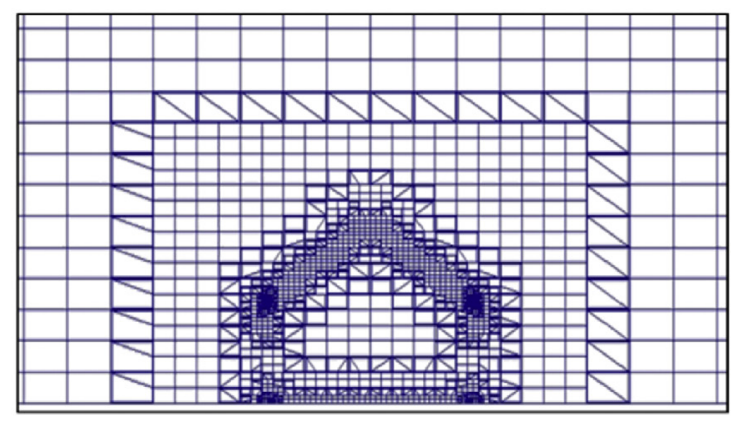

c)

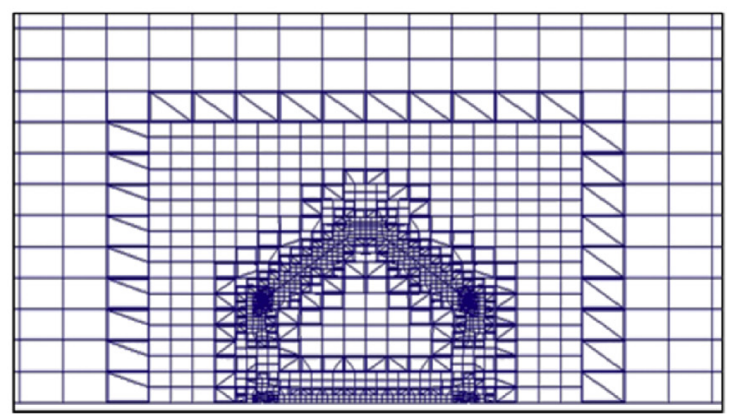

Fig. 2 - Meshing processes using SnappyHexMesh utility: a) initial background mesh, b) cell-splitting by surfaces and regions, and c) improvement of the mesh quality around surface geometries.

\subsubsection{Building and terrain modelling}

A building structure given by users is modelled by STL files that describe the surface geometry of a three-dimensional object in the form of a combination of triangulated surfaces. The easiest method for the triangulation was to change each wall into a regular grid of quadrilateral face elements and subsequently split the quadrilateral elements diagonally into 


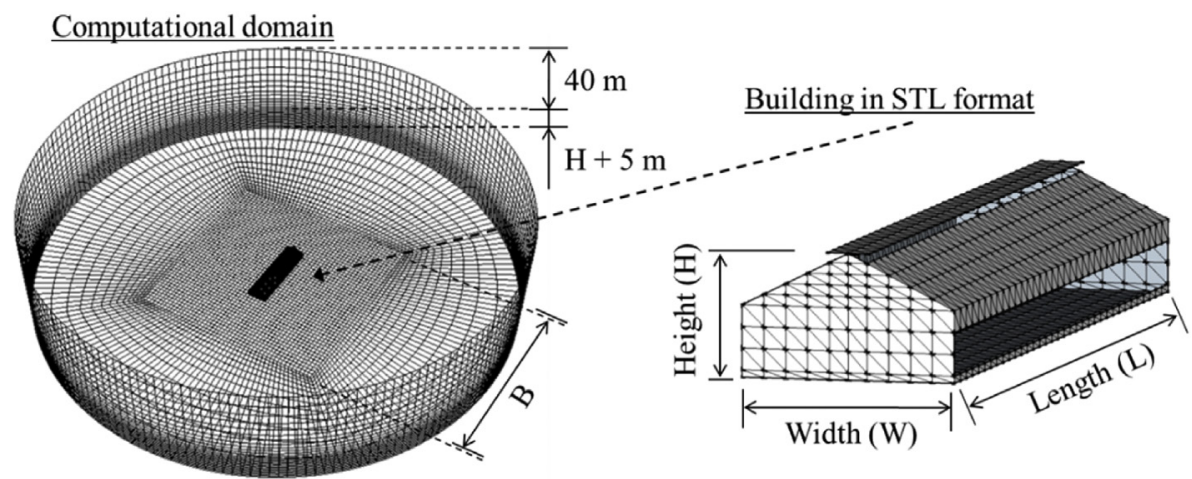

Fig. 3 - Sketches showing computational domain, its background meshing, and building geometry in STL format. B is the size of the inner box and determined as $B=2 \sqrt{W^{2}+L^{2}}+10$. The radius of the computational domain $\left(R_{d}\right)$ was designed as $R_{d}=B \sqrt{2} / 2+50$.

pairs of triangular faces. When ventilation openings exist on the wall, triangular faces located in the openings were omitted from the STL file.

The terrain is modelled from a digital elevation model (DEM) that should be given by a user. A dataset of the DEM is a two-dimensional array; therefore, by simply connecting each adjacent data point, the DEM becomes a grid of quadrilateral face elements. The remaining triangulation procedures are the same as the case of building structures.

\subsubsection{Computational domain and meshes}

Creating a computational domain and meshes was described in detail by (Hong et al., 2017). The size of the domain and meshes is dependent on the size of the building to achieve sufficient surrounding volume. For most agricultural buildings, the size of the computational domain satisfies the recommended domain size, which is generally $5 \mathrm{H}$ in height and $15 \mathrm{H}$ in length (Bjerg, Cascone, et al., 2013; Tominaga et al., 2008). An inner box of size $B$ and $(H+5)$ is created at the centre of the domain to yield finer meshes around the target building.

A cylindrical domain was built as the computational domain and was initially filled with structured hexahedron cells. The "blockMesh" and "snappyHexMesh" utility of the OpenFOAM were used to create meshes, as shown in Fig. 4. A user-defined terrain surface can also be included in the

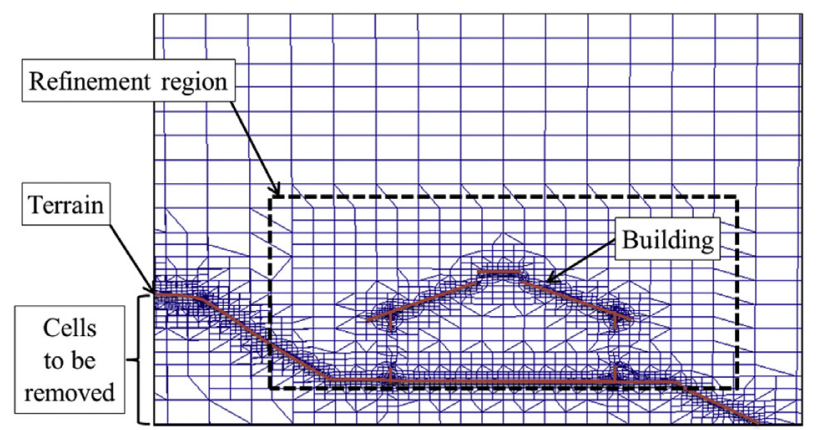

Fig. 4 - Process of splitting cells in the computational domain using snappyHexMesh utility. computational domain before the refinement stages and treated the same as the building walls. After the refinement stages, the cells beneath the terrain surface were removed because they were not required for the air flow calculation.

The mesh size can be selected by users among 10 predefined mesh levels (Hong et al., 2017). The mesh size of the lowest level is four times the overall mesh, and eight times for near-wall meshes larger than those of the highest level. Every refinement process halves the mesh size. After the refinement stages, the "checkMesh" utility of the OpenFOAM is executed to detect bad-quality cells that are subsequently removed from the mesh to avoid numerical errors using the "setSet" and "subsetMesh" utilities (Ivchenko, 2011).

\subsection{Numerical schemes}

The governing equations to solve the airflows are the steadystate Reynolds-averaged Navier-Stokes (RANS) equations. The used numerical schemes are the same as those in (Hong et al., 2017). The turbulence quantities are modelled by twoequation $\mathrm{k}-\varepsilon$ models, which are the standard $\mathrm{k}-\varepsilon$ model, the RNG (renormalisation group theory) $\mathrm{k}-\varepsilon$ model, the realisable $\mathrm{k}-\varepsilon$ model, and the low Reynolds number (low Re) $\mathrm{k}-\varepsilon$ model.

The RANS equations combined with the energy equation are solved by the "buoyant Boussine sq Simple Foam" solver, which describes the buoyant and turbulent flows of incompressible fluids and the Boussinesq approximation. In this study, new solvers, "buoyantBoussinesqSimpleFoamAM" (BBSFA) and "buoyantBoussinesqSimpleFoamPM" (BBSFP) were developed to produce more realistic simulation results for animals and plants, respectively. The new solvers modified the "buoyantBoussinesqSimpleFoam" solver by adding the source terms to the energy and momentum equations to realise the heat generation and momentum sink from animals and plants, respectively.

The equations used for the BBSFA and BBSFP solvers are the momentum equation (1), continuity equation (2), and energy equation (3).

$\nabla(\mathrm{UU})-\nabla\left(v_{\mathrm{T}} \nabla \mathrm{U}\right)=-\nabla \mathrm{p}-\left[1-\beta\left(\mathrm{T}-\mathrm{T}_{\text {ref }}\right)\right] g+\mathrm{S}_{\mathrm{U}}$ 
$\nabla \cdot \mathrm{U}=0$

$\nabla(\mathrm{UT})-\mathrm{T} \nabla \mathrm{U}-\nabla\left(\kappa_{\mathrm{eff}} \nabla \mathrm{T}\right)=\mathrm{S}_{\mathrm{T}}$

where $U$ is the velocity $\left(\mathrm{m} \mathrm{s}^{-1}\right), v_{\mathrm{T}}$ is the kinematic turbulent viscosity $\left(\mathrm{m}^{2} \mathrm{~s}^{-1}\right), \mathrm{p}$ is the kinematic pressure $\left(\mathrm{m}^{2} \mathrm{~s}^{-2}\right), \beta$ is the thermal expansion coefficient $\left(\mathrm{K}^{-1}\right), g$ is the gravitational acceleration $\left(\mathrm{m} \mathrm{s}^{-2}\right), \mathrm{T}$ is the temperature $(\mathrm{K}), \mathrm{T}_{\text {ref }}$ is the reference temperature $(\mathrm{K}), \kappa_{\text {eff }}$ is the effective thermal diffusivity $\left(\mathrm{m}^{2}\right.$ $\left.\mathrm{s}^{-1}\right), \mathrm{S}_{U}$ is the source term for the kinematic pressure loss by animals or plants $\left(\mathrm{m} \mathrm{s}^{-2}\right)$, and $S_{\mathrm{T}}$ is the source term for the sensible heat generation by animals or plants $\left(\mathrm{K} \mathrm{s}^{-1}\right)$.

The source term, $S_{U}$, is derived by the Darcy-Forchheimer equation.

$\mathrm{S}_{\mathrm{U}}=-\left(v \mathrm{C}_{1}+\frac{1}{2} \mathrm{UC}_{2}\right) \mathrm{U}$

where, $C_{1}$ and $C_{2}$ are the parameters related to viscous and inertial resistances $\left(\mathrm{m}^{-2}\right.$ and $\left.\mathrm{m}^{-1}\right)$, respectively.

The source term, $S_{T}$, was calculated using different forms in the BBSFA and BBSFP solvers because animals and plants involve completely different energetic and physiological mechanisms, as explained in section 3.4.

\subsection{Sensible heat generation}

Sensible heat generation by animals and plants are calculated from their energetic balance models. Latent heat transfer owing to respiration or transpiration is also involved in the total energy balance, but air humidity is not modelled in this program because water vapour and latent heat do not affect the airflow patterns significantly compared to thermal effects.

A few mathematical models described the processes of heat transfer from animals to their surroundings based on the physics of heat transfer (Norton, Grant; Fallon, \& Sun, 2010; Turnpenny, McArthur, Clark, \& Wathes, 2000). For plants, especially the tomato crop, energetic activities were described in (Boulard et al., 2004; Boulard \& Wang, 2002; Demrati et al., 2007; Wang \& Boulard, 2000). The details of the mathematical modelling of sensible heat generation by animals and plants can be found in Appendices A and B, while equation (5) was used to describe the source term, $S_{T}$.

$\mathrm{S}_{\mathrm{T}}=\left\{\begin{array}{cc}\frac{\mathrm{A}_{\mathrm{c}} \mathrm{n}_{\mathrm{a}} \mathrm{Q}_{\mathrm{a}}}{\rho \mathrm{C}_{\mathrm{p}} \mathrm{V}_{\mathrm{z}}}, \text { for animals } \\ 2 \mathrm{LAI}_{\mathrm{V}} \frac{\mathrm{T}_{\mathrm{l}}-\mathrm{T}_{\mathrm{a}}}{\mathrm{r}_{\mathrm{a}}}, & \text { for plants }\end{array}\right.$

where $A_{c}$ is the surface area of the animal $\left(m^{2}\right), n_{a}$ is the number of animals in the building, $V_{z}$ is the volume of the animal the zone in the building $\left(\mathrm{m}^{3}\right)$ calculated by the product of the floor area and the animal height $\left(H_{a}\right), L I_{v}$ is the volumetric leaf area density $\left(\mathrm{m}^{2} \mathrm{~m}^{-3}\right), \mathrm{T}_{l}$ and $\mathrm{T}_{a}$ are the temperatures of leaf and air, respectively $(\mathrm{K})$, and $r_{a}$ is the aerodynamic resistance of leaf $\left(\mathrm{s} \mathrm{m}^{-1}\right)$.

\subsection{Momentum loss}

The existence of animals and plants reduces the momentum of airflows passing through the animal zone or plant zone. $C_{1}$ and $C_{2}$ are factors that determined the effect on the flow resistance. In a turbulent flow, the pressure decrease owing to viscous resistance is small compared to the pressure decrease by inertial resistance and can be neglected (Sase, Kacira, Boulard, \& Okushima, 2012). Therefore, the momentum sink is almost dependent on the inertial resistance.

The momentum loss in the animal-occupied zone is described by simple physical concepts. When wind flows to an animal, the amount of drag force acting on the animal can be simply calculated as

$F_{d}=\frac{1}{2} \rho v^{2} C_{d} A_{p}$

where $F_{d}$ is the drag force acting on an animal $\left(\mathrm{kg} \mathrm{m} \mathrm{s}^{-2}\right), C_{d}$ is the drag coefficient, and $A_{p}$ is the cross-sectional area projected in the direction of the airflow $\left(\mathrm{m}^{2}\right)$.

When the air exerts a force on the animal, the animal simultaneously exerts an identical force but in the opposite direction of the airflow, as described by Newton's third law. When $n_{a}$ animals exist in a zone with a volume of $V_{z}$, the total force acting on the air that correspond to the momentum loss with respect to time is calculated in a unit volume as follows:

$\mathrm{S}_{\mathrm{U}}=-\frac{\mathrm{n}_{\mathrm{a}} \mathrm{F}_{\mathrm{d}}}{\rho \mathrm{V}_{\mathrm{z}}}=-\frac{n_{a} \mathrm{~A}_{p}}{2 \mathrm{~V}_{\mathrm{z}}} C_{d} \mathrm{v}^{2}$

Similarly, the inertial resistance of a plant is estimated from the drag coefficient of the plant using Wilson's equation that describes the relationship between the drag coefficient of the plant and the pressure loss (Wilson, 1985) (Wilson, 1985).

$\mathrm{S}_{\mathrm{U}}=-\mathrm{LAI}_{\mathrm{v}} \cdot \mathrm{C}_{\mathrm{d}} \mathrm{v}^{2}$

This yields the relationship between $C_{d}$ and $C_{2}$.

$C_{2}= \begin{cases}\frac{\mathrm{n}_{\mathrm{a}} \mathrm{A}_{\mathrm{p}}}{\mathrm{V}_{\mathrm{z}}} \mathrm{C}_{\mathrm{d}}, & \text { for animals } \\ 2 \mathrm{LAI}_{\mathrm{v}} \mathrm{C}_{\mathrm{d}}, & \text { for plants }\end{cases}$

\subsection{Boundary conditions}

For boundary conditions within the atmospheric boundary layer (ABL), vertical profiles of the wind speed and turbulence quantities can be designed in two forms, which are nonuniform profiles or uniform constant values. When the wind speed and turbulence kinetic energy, $\mathrm{k}$, are given as a constant value that does not vary over the $A B L$, the given values are used as a fixed value for each inlet boundary condition. The turbulence dissipation rate at the inlet boundaries is set as (Burton, Jenkins, Sharpe, \& Bossanyi, 2011; Burton, Sharpe, Jenkins, \& Bossanyi, 2001):

$\varepsilon=\rho C_{\mu} \frac{k^{2}}{\mu}\left(\frac{\mu_{t}}{\mu}\right)^{-1}$

where, $C_{\mu}$ is the dimensionless constant of 0.09 , and $\mu_{t} / \mu$ is the turbulent viscosity ratio that is assumed as 100 .

When a log profile is provided for the wind speed as shown in (11), the friction velocity, $u_{*}$, is calculated by a user-defined reference wind speed and used to design the vertical profiles of turbulence quantities. The vertical distributions of the mean wind speed, the turbulence kinetic energy and its dissipation rate, and the turbulent viscosity for the inlet 
boundaries are shown as follows (Burton et al., 2001) (Burton et al., 2001):

$\mathrm{U}(\mathrm{z})=\frac{\mathrm{u}_{*}}{\mathrm{~K}} \ln \left(\frac{\mathrm{z}+\mathrm{z}_{0}}{\mathrm{z}_{0}}\right)$

$\mathrm{k}(\mathrm{z})=\frac{\mathrm{u}_{*}^{2}}{\sqrt{\mathrm{C}_{\mu}}}\left(1-\frac{\mathrm{z}}{\mathrm{h}_{\mathrm{g}}}\right)^{2}$

$\varepsilon(\mathbf{z})=\frac{\mathrm{u}_{*}{ }^{3}}{\mathrm{~K}\left(\mathrm{z}+\mathrm{z}_{0}\right)}$

$\mu_{\mathrm{t}}(\mathrm{z})=\mathrm{u}_{*} \mathrm{Kz}\left(1-\frac{\mathrm{z}}{\mathrm{h}_{\mathrm{g}}}\right)^{4}$

where $h_{g}$ is the geostrophic plane height of the ABL that is calculated as

$\mathrm{h}_{\mathrm{g}}=\frac{\mathrm{u}_{*}}{12 \Omega \sin (|\Lambda|)}$

where $\Omega$ is the angular velocity of the Earth's rotation $\left(7.2722 \times 10^{-5} \mathrm{rad} \mathrm{s}^{-1}\right)$, and $\Lambda$ is the latitude of the position.

The boundary conditions at the inlet, outlet, top, ground, and building walls are set as shown in Table 1. The side boundary of the cylindrical domain is divided into 16 parts representing the 16 wind directions. When the wind direction is given, the windward 8 parts are set up as inlet while the leeward 8 parts are set up as outlet.

\subsection{Calculating LMA and LMR}

The local mean age (LMA) and local mean residual lifetime (LMR) were used to evaluate the efficiency of ventilation (Kwon et al., 2011). During the ventilation process, fresh air can reach any point through various pathways. The LMA of air at a given point refers to the average time of streams that the fresh air travels from the inlet to the point, while the LMR of air is the average time of streams that the old air at the given point reaches the exit.

After obtaining a convergent solution for the velocity, the LMA and LMR are calculated by the method proposed by Park, Lee, and Hong (2014). In this method, the distribution of the LMA is calculated by solving the passive scalar transport equation for the time scalar, $\varphi$, with the uniform production of the time scalar over the ventilation space as shown in (16).

$\frac{\partial \varphi}{\partial \mathrm{t}}+\nabla(\mathrm{U} \varphi)-\nabla\left(\mathrm{D}_{\mathrm{T}} \nabla \varphi\right)=\mathrm{S}_{\varphi}$ where $\varphi$ is the time scalar (s), $D_{T}$ is the diffusivity of the time scalar $\left(\mathrm{m}^{2} \mathrm{~s}^{-1}\right)$, and $\mathrm{S}_{\varphi}$ is the source term for the time scalar.

Assuming that the time scalar is transported in the opposite direction to the airflow, i.e., the air travels from the outlets to inlets, the solutions of the time scalar transport equation imply the distribution of time that air travels from the outlets to the internal positions, corresponding to the LMR. Therefore, the LMR is calculated by replacing $U$ with $-U$ in the second term of (16), which is the convection term, and by solving the revised scalar transport equation. The two equations for the LMA and LMR are introduced into a new solver, "ageOfAirFoam" developed in this study.

\subsection{Management of simulation}

Creating the OpenFOAM case is the fundamental procedure for CFD simulation. The OpenFOAM case consists of three folders, each of which contains the files with proper file names and are written with the syntax rules of the OpenFOAM. To create the OpenFOAM case, data obtained from the inputs are written in the right locations of the files.

As shown in Fig. 5, the wind conditions given by users are used to build the boundary conditions. Each involved quantity, such as velocity, pressure, turbulent quantities, and energy, is defined by individual files, and all files are placed in the "0" folder. The building geometry and terrain data are modelled as STL files in the subfolder of the "constant" folder. Some constants to be used in the governing equations and parameters to calculate the source terms for heat and momentum owing to animals or plants are also written in the "constant" folder. The "system" folder includes files related to the meshing techniques, selected numerical schemes and algorithms, calculation time and conditions, and parallel processing. Apart from the files above, some files are included in the OpenFOAM case to automate the simulation processes.

Based on the OpenFOAM case file, the CFD simulation was conducted through a typical procedure, i.e., mesh generation and poor mesh removal (section 3.2), solution initialisation and inlet boundary condition revision, primary calculations (section 3.3 3.6), and LMA and LMR calculations (section 3.7), as shown in Fig. 5. Each step is executed by executing the suitable OpenFOAM utility.

Among the CFD procedures, the mesh generation, primary calculations, and LMA and LMR calculations can be performed by parallel computing. When parallel processing is activated, additional actions are performed before and after each step. Before the step, the computational domain and all data fields were decomposed into the desired number of partitions. Decomposition was performed using the hierarchical method

Table 1 - Boundary conditions for velocity (V), pressure (p), turbulence kinetic energy (k), turbulence dissipation rate ( $\varepsilon$ ), turbulent viscosity $(\mu t)$, and temperature $(T)$ at inlet, outlet, top, ground, and building structures.

\begin{tabular}{|c|c|c|c|c|c|}
\hline & Inlet & Outlet & Top & Ground & Building \\
\hline $\mathrm{V}$ & Fixed value & Outlet & slip & Fixed value $(U=0)$ & Fixed value $(U=0)$ \\
\hline $\mathrm{P}$ & Zero gradient & Fixed value & slip & Zero gradient & Zero gradient \\
\hline $\mathrm{k}$ & Fixed value & Zero gradient & slip & Wall function & Wall function \\
\hline$\varepsilon$ & Fixed value & Zero gradient & slip & Wall function & Wall function \\
\hline$\mu_{\mathrm{t}}$ & Calculated & Calculated & Calculated & Wall function & Wall function \\
\hline $\mathrm{T}$ & Fixed value & Outlet & slip & Zero gradient & Zero gradient \\
\hline
\end{tabular}




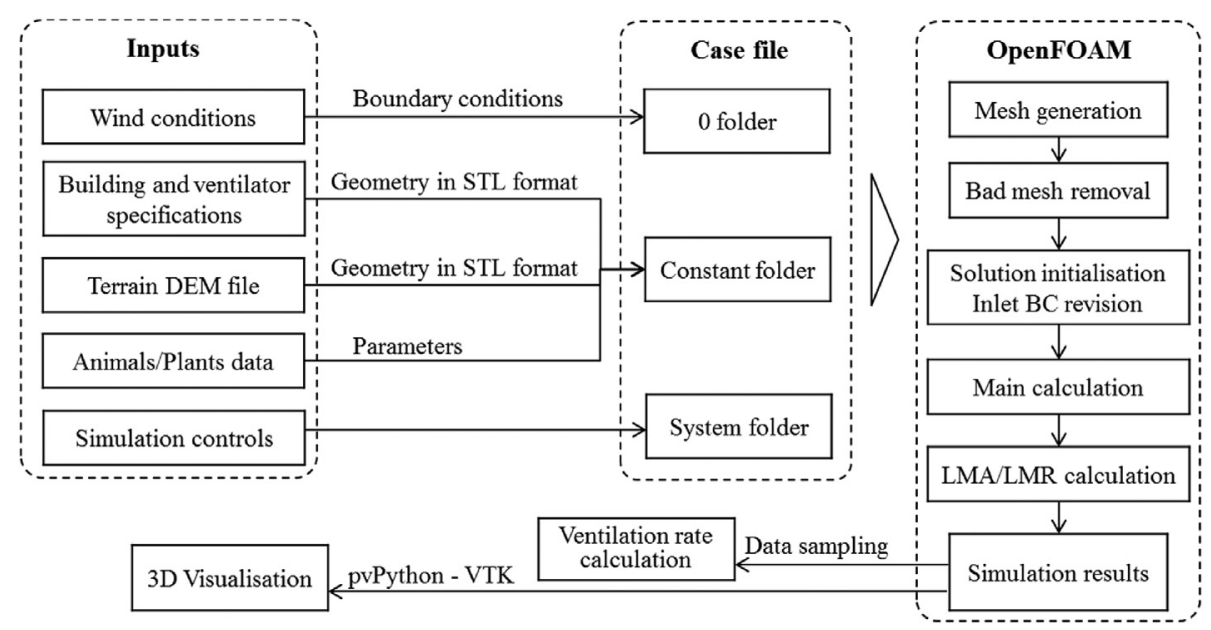

Fig. 5 - CFD simulation and automation pipeline.

in which the domain is split into the specified number of pieces in the $\mathrm{x}-, \mathrm{y}-$, and $\mathrm{z}$-directions. Meanwhile, the partitions are reconstructed as before after the mesh generation or when the calculations are completed. Parallel computing is performed by the freely available MPICH2 (version 1.4.1p1, http://www.mpich.org/).

\section{HNVR-SYS: primary functionalities}

This section briefly describes the primary modules and user interfaces available in HNVR-SYS. Figure 6 presents several GUIs that comprise the program. A complete overview and more details of the program are provided in the HNVR-SYS tutorial and documentation.

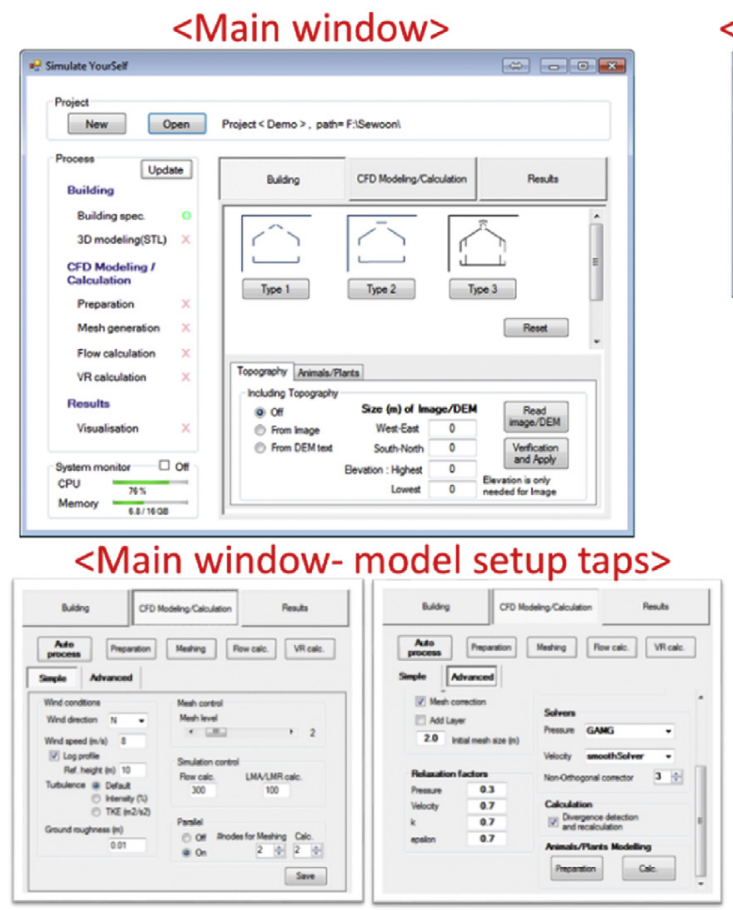

\subsection{Inputs and options for CFD simulation}

The automation tool requires information about the geometry, ABL, and simulation methodology that should be provided before it runs. The geometrical information contains dimensions of a building structure and its ventilation openings, terrain map and its information, and animals/plants data if they exist in the building. The ABL information includes the wind speed as a constant value or a log profile, wind direction, turbulence level, and ground roughness. The simulation information involves the controls of mesh generation, CFD computation, and parallel computing environment.

The inputs that should be provided or selected by the users are as follows.
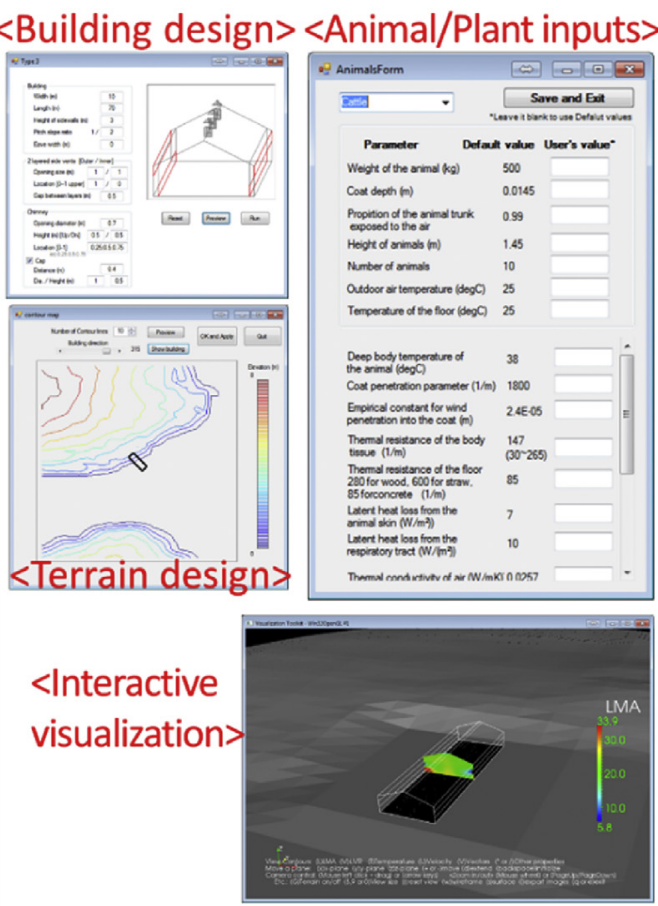

Fig. 6 - HNVR-SYS graphical user interfaces. 
- Building: Selectable between six building types, dimensions of walls and roof, roof slope ratio or curvature, eave length, and ventilation opening size and location.

- Terrain (optional): DEM file or DEM image file, terrain size, highest/lowest elevation (if a DEM image file is given), location, and direction of the building.

- Animals/plants (optional): Animal type (cattle, pigs, poultry) and data presented in Table 2; plant data presented in Table 3.

- Wind conditions: Wind direction (16 directions), wind speed (log profile is selectable), reference height (if a log profile is selected), turbulence kinetic energy (or turbulence intensity), ground roughness.

Simulation controls: Mesh size, meshing technique (poorquality correction, adding layer), turbulence model (among four $\mathrm{k}-\varepsilon$ models), numerical schemes (GAMG, PCG, smoothSolver, PBiCG), relaxation factors, number of computation steps, number of computing nodes (if parallel processing is activated).

\subsection{Result visualization}

The simulation results are analysed in two aspects. One is to show the ventilation rates at each ventilation opening and the overall ventilation rate. The other is to the visualise airflow patterns in and around the building, and the distributions of any physical properties in the building. The visualisation tool was coded in Python to render the simulation results in the VTK format as a three-dimensional visual object.

The visualisation application creates a view window and represents the building outline and, if desired, the terrain surface in the view window. It also creates a slice to show variable values over a plane on which the LMA, LMR, velocity, pressure, temperature, turbulence quantities, and airflow
Table 3 - Parameters and their default values for plant modelling. The values are from Boulard et al. (2004); Hong (2008) but are user definable.

\begin{tabular}{lc} 
Parameter & Default values (cattle/pigs/poultry) \\
\hline$L A I$ & 3 \\
$h_{p}$ & 1.8 \\
$L$ & 0.25 \\
$T_{a i}$ & 298.15 \\
$w_{a}$ & $40 \%$ \\
$R_{\text {net }}$ & 600 \\
$a$ & 2.7 \\
$b$ & $1 / 17.5$ \\
$K_{c}$ & 0.75 \\
$r_{s, \text { min }}$ & 30 \\
$D_{\text {max }}$ & 1000 \\
$\rho C_{p}$ & 1220 at $20^{\circ} \mathrm{C}$ \\
$C_{d}$ & 0.26 \\
Relaxation & 0.2 \\
\# iterations & 25 \\
\hline
\end{tabular}

vectors are found, as shown in Fig. 7. The sliced plane can be bounded into the building and extended to the exterior of the building; the location and direction of the slice are also controllable using a keyboard and mouse. The view window allowed for users to perform manipulations interactively, such as zoom in, zoom out, rotate, and move the viewpoint using the mouse.

\subsection{Procedure to use HNVR-SYS}

A CFD problem can be solved by the basic procedural steps as follows. 1) Determine the important features of the problem that a user wishes to solve. 2) Select the building type, and input the dimensions of the building and its ventilation openings. 3) If applicable, load a DEM file to create a terrain surrounding the building. Establish the direction of the

Table 2 - Parameters and their default values for animal modelling. The values are from Turnpenny, Wathes, Clark, and McArthur (2000) but are user definable.

\begin{tabular}{ll} 
Parameter & \multicolumn{1}{c}{ Default values (cattle/pigs/poultry) } \\
\hline$A_{c}$ & $0.09 \mathrm{~m}_{b}^{0.67} / 0.086 \mathrm{~m}_{b}^{0.67} / 0.081 \mathrm{~m}_{b}^{0.67}$, while $\mathrm{m}_{b}$ is the mass (liveweight) of the \\
& animal $(\mathrm{kg})$ \\
$m_{b}$ & $500 / 70 / 1$ \\
$d$ & $2 \sqrt{\frac{A_{c}}{4 \pi}}$ by assuming the animal as a sphere \\
& $1.45 / 0.65 / 0.45$ \\
$H_{a}$ & $38^{\circ} \mathrm{C} / 39^{\circ} \mathrm{C} / 41^{\circ} \mathrm{C}$ \\
$\mathrm{T}_{b d}$ & $1800 / 1800 / 500$ \\
$p$ & $2.4 \times 10^{-5} / 2.4 \times 10^{-5} / 9.1 \times 10^{-6}$ \\
$C^{\prime}$ & $147 / 130 / 250$ \\
$r_{t}$ & 85 for concrete \\
$r_{f l r}$ & $7 / 10 / 5$ \\
$E_{c}$ & $10 / 20 / 5$ \\
$E_{r}$ & 0.0257 at $20{ }^{\circ} \mathrm{C}$ \\
$k_{a}$ & 0.48 \\
$B$ & 0.25 \\
$m$ & 1 \\
$\varepsilon$ & 1220 at $20^{\circ} \mathrm{C}$ \\
$\rho C_{p}$ & 1 \\
$C_{d}$ & 0.8 \\
Relaxation & 9 \\
$\#$ iterations & should be given \\
$n_{a}, T_{r}, T_{f l r}$ &
\end{tabular}




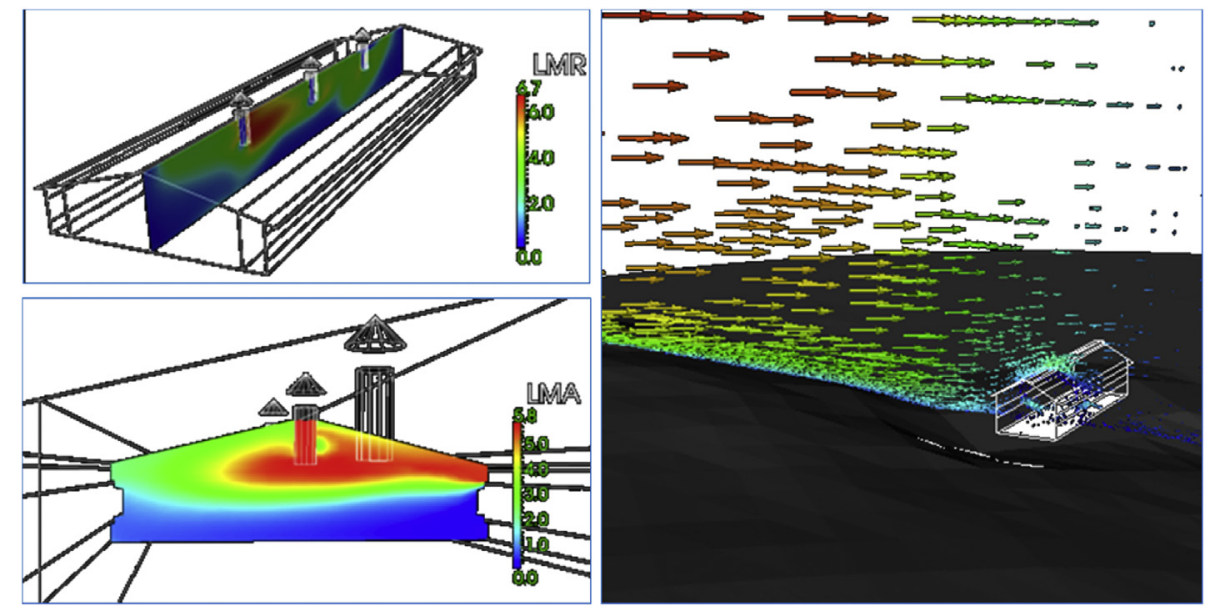

Fig. 7 - Three-dimensional visualisation of the simulation results by the Paraview Python script.

building. 4) If applicable, select the internal object between animals and plants, and assign physiological parameters to them. 5) Input the wind speed, turbulence kinetic energy, and ground roughness for the inlet boundary conditions. Activate or deactivate the log profile option. 6) Select the mesh size among 10 levels. 7) Establish the calculation time. 8) If applicable, activate the parallel processing, and set the number of computing nodes. 9) If applicable, more technical options can be established in the advanced tap, such as the turbulence model, mesh options, numerical schemes for discretisation, and relaxation factors. 10) Execute the CFD processes by clicking the "auto process" button or by clicking four separate buttons sequentially. 11) Examine the simulation results.

In step 2, only six building types are available, but more structural types will be included in the program in the future. Although the simulation is automatically performed by the program, it is open to the user's intervention because all files and folders of the OpenFOAM case are freely accessible.

\section{Examples of HNVR-SYS applications}

The developed program was used, as part of a validation study, to examine the accuracy of the OpenFOAM simulations by Hong et al. (2017). In its current state, the program comprises three building types, and Hong et al. (2017) compared the simulation results with wind tunnel measurements. The OpenFOAM simulations yielded good agreement with the measured air velocities. Two examples given below show further validity of the developed program with regard to the prediction of ventilation rate and indoor air temperature.

\subsection{NV greenhouse}

In the first example, an even-span greenhouse of size $9 \mathrm{~m}(\mathrm{~W}) \times 45 \mathrm{~m}(\mathrm{~L}) \times 4.95 \mathrm{~m}(\mathrm{H})$ was modelled. The building contained two continuous side vents and angled roof vents, as shown in Fig. 8. S. Lee et al. (2018) calculated the ventilation rates according to various wind directions $\left(0^{\circ}, 45^{\circ}\right.$, and $\left.90^{\circ}\right)$ and wind speeds $\left(1.0,2.5\right.$, and $\left.5.5 \mathrm{~m} \mathrm{~s}^{-1}\right)$ using a commercial CFD code and validated the simulated results through wind tunnel measurements. The same structure and wind conditions were modelled using the HNVR-SYS with a mesh level of three and the RNG $\mathrm{k}-\varepsilon$ turbulence model; the results are in good agreement with those by S. Lee et al. (2018), showing an average relative error of $11.8 \%$ and an RMSE error of $0.43 \mathrm{~min}^{-1}$ (Fig. 9).

\subsection{NV dairy barn}

In the second example, an NV dairy barn studied by Samer et al. (2011) was tested. The dairy barn of size $34.2 \mathrm{~m}(\mathrm{~W}) \times 96.15 \mathrm{~m}(\mathrm{~L}) \times 10.73 \mathrm{~m}(\mathrm{H})$ was ventilated primarily through adjustable curtains on the long sidewalls and open ridge slots, and accommodated 364 dairy cows. Samer et al. (2011) measured the air temperatures and ventilation rates in the summer, among which five consecutive measurements were compared to the simulation. HNVR-SYS was used to model the dairy barn where all the inputs were the same as the experimental conditions of Samer et al. (2011). Wind speed varied from 0.3 to $3.5 \mathrm{~m} \mathrm{~s}^{-1}$ in the measurement, and the average wind speed of $1.9 \mathrm{~ms}^{-1}$ was tested in the simulation. Figure 10 shows the comparison of the indoor air

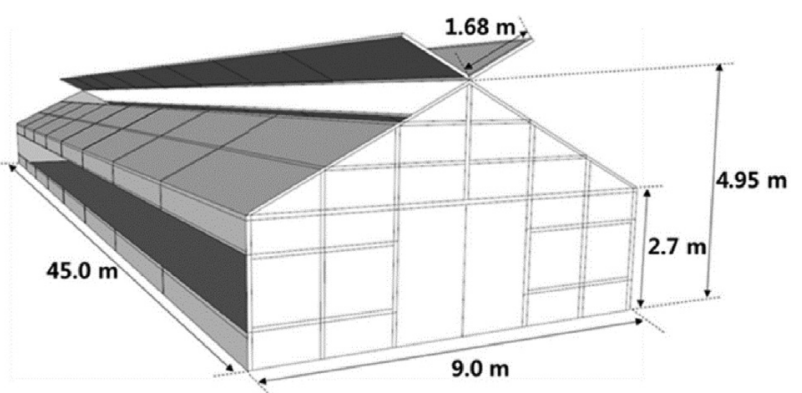

Fig. 8 - Schematic diagram of the even-span greenhouse (S. Lee et al., 2018). 


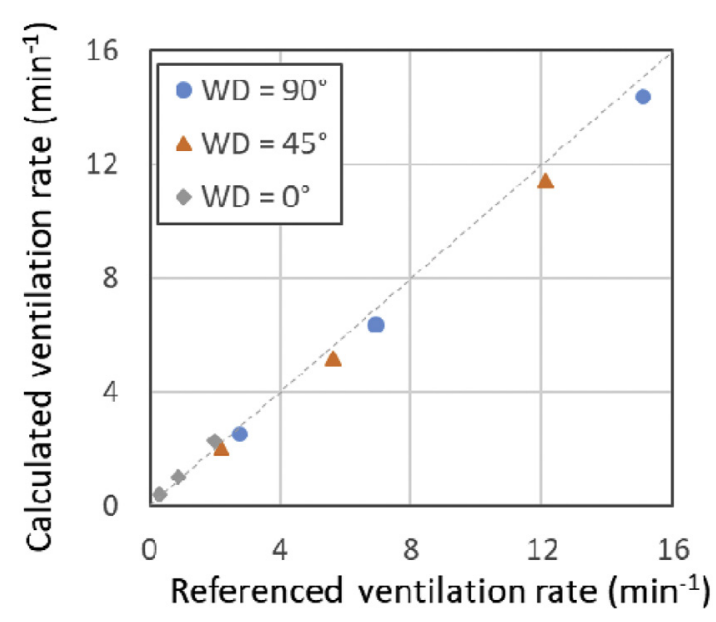

Fig. 9 - Comparison of ventilation rates obtained by the reference (S. Lee et al., 2018) and HNVR-SYS of this study. WD stands for wind direction, and $90^{\circ}$ indicates the wind blowing perpendicular to the side vent.

temperature increase owing to heat generation by animals and the ventilation rates between five measurements and HNVR-SYS result. The air temperature was less increased in the simulation, and this may be because other heat sources besides animals' body heat were not considered in the simulation. In the summer, air temperature near the ground is generally higher than that measured at weather stations due to solar radiation. While the hot air might enter the barn through the side openings, the simulation considered the air temperature measured at the weather stations as the outdoor air temperature, which would not heat up the barn up to the desired level. The simulated ventilation rate was also slightly smaller than the ones measured by the tracer gas method. It was because the experimental barn opened gates and doors at the front side of the barn through summer seasons, which is a practice for common naturally-ventilated barns to allow more ventilation air flows into the barn. Notwithstanding the slight underestimates, the simulated results were still within the range of measured values, indicating that the HNVR-SYS produced a reasonable approximation of heat generation by animals, the corresponding indoor air temperature, and the ventilation rate of the naturally-ventilated barn.

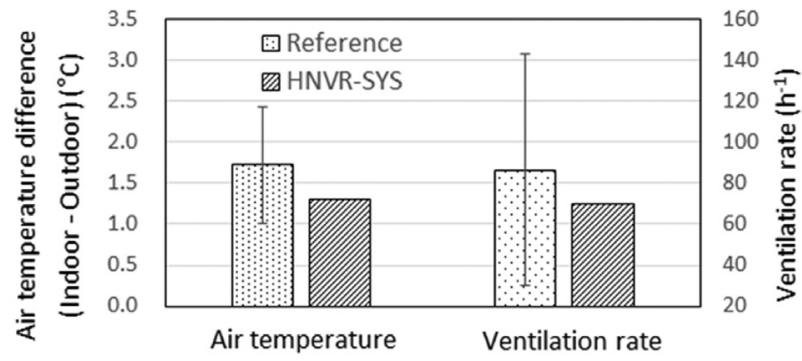

Fig. 10 - Comparison of indoor air temperature rise and ventilation rate between the reference (Samer et al., 2011) and HNVR-SYS result.
In the two examples, results obtained by HNVR-SYS were in good agreement with those in the references. In particular, a remarkable benefit from HNVR-SYS was that the program reduced time and effort by automating the mesh generation, which is the most time consuming part for engineering problems generally. Only a few hours were required to complete the CFD computation from scratch, while a few days are required for any CFD tool to complete the pre-, main-, and post-processes.

\section{Conclusions and further developments}

In this study, an automatic simulation tool using CFD for non-experts was developed to predict the ventilation rate of NV buildings. OpenFOAM and ParaView VTK were used for CFD simulation and visualisation, respectively, because they are free and open-source software. The simulation tool, HNVR-SYS, was developed using Microsoft VB and Python to automate the general processes of the CFD simulation, such as the building geometry, meshing and computing, and GUIs for users. The GUI allowed the user to easily design the structure and surrounding terrain, and create wind conditions that were subsequently used to build the boundary conditions of the simulation model automatically.

HNVR-SYS provides general users, such as farmers, companies, and researchers, with quick and practical solutions to simulate the ventilation process without any help from CFD experts but with the advantage of ensuring a similar level of accuracy by the predeveloped procedures and reduced time and effort. It can model the effect of a terrain shape on the atmospheric boundary layer and natural ventilation easily, and simulate the effect of animals or plants in a thermal environment and buoyancy-driven ventilation.

This study proposed a new simulation idea for encouraging people from CFD technique. While CFD is still a highly technical method, further development of CFD automation would enable non-CFD experts to apply aerodynamic knowledge to their various fields of research. The first step can be using ventilation prediction in a mechanically ventilated agricultural building, which still accounts for the majority of agricultural buildings. The emission of $\mathrm{NH}_{3}$ and dust from animal houses and their dispersion to downwind communities is becoming a serious concern and can benefit from the program. More building types that are typically used should be included in the program to be further developed. Moreover, validation tests should be conducted persistently.

\section{Acknowledgement}

This work was supported by the Marie Curie Action: "International Incoming Fellowships" of the European Union (FP7PEOPLE-2012-IIF), Project No. 331197. The program and its documentation are distributed through the project website (http://www.NatVent-CFD.com). 


\section{Appendix A. Heat Source from Animals}

The heat transfer from animals can be described in three layers: the layer between the body core and the skin, the layer between the skin and the hair-coat surface, and the layer between the hair-coat surface and the air. When an animal is in thermal equilibrium, heat is transferred in the first layer through the body tissue and blood by conduction, and convection. In the second layer, heat is transferred through the hair-coat by conduction, convection, and radiation. Heat is also transferred in the form of latent heat from the skin. In the third layer, heat is transferred to the air by convection and radiation. Apart from the three layers above, the animal can lose its body heat through its respiratory tract and through a direct contact with the floor.

The rate of heat transfer depends upon the temperature difference, resistance to heat flow, and additional heat transfers, as shown in (A-1).

$\mathrm{Q}=\left(\mathrm{T}_{1}-\mathrm{T}_{2}\right) / \mathrm{r}+\mathrm{Q}_{3}$

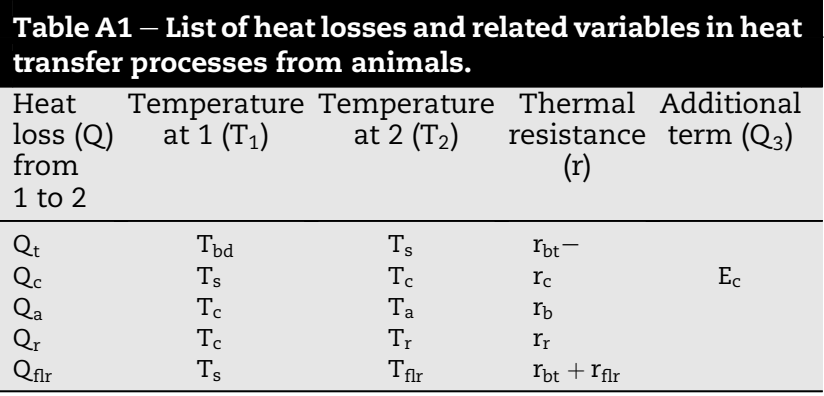

In Table A1, $Q_{t}, Q_{c}$, and $Q_{f l r}$ are the heat losses from the body core to the skin, from the skin to the hair-coat surface, and from the skin to the floor $\left(\mathrm{W} \mathrm{m}^{-2}\right) . \mathrm{Q}_{a}$ and $\mathrm{Q}_{r}$ are the convective heat loss and radiative heat loss from the hair-coat surface to the air, respectively $\left(\mathrm{W} \mathrm{m}^{-2}\right) . \mathrm{T}_{b d}, \mathrm{~T}_{s}, \mathrm{~T}_{c}, \mathrm{~T}_{a}, \mathrm{~T}_{r}$, and $\mathrm{T}_{\text {flr }}$ are the temperatures of the body core, skin, hair-coat surface, surrounding air, radiant enclosure, and floor $(\mathrm{K}) . r_{b t}, r_{c}$, and $r_{f l r}$ are the thermal resistances of the body tissue, hair-coat, and floor $\left(\mathrm{m}^{2} \mathrm{~K} \mathrm{~W}^{-1}\right) . r_{b}$ and $r_{r}$ are the thermal resistance and radiative resistance of the boundary layer on the hair-coat surface, respectively $\left(\mathrm{m}^{2} \mathrm{~K} \mathrm{~W}^{-1}\right) . E_{c}$ is the latent heat loss from the skin (W m ${ }^{-2}$ ).

The resistances, $r_{t}$ and $r_{f l r}$, are the characteristics of an animal, while $r_{c}, r_{a}$, and $r_{r}$ are influenced by the surrounding air conditions.

$$
\begin{aligned}
& \mathrm{r}_{\mathrm{b}}=\frac{\mathrm{d}}{\mathrm{k}_{\mathrm{a}} \mathrm{N}_{\mathrm{u}}} \\
& \mathrm{r}_{\mathrm{r}}=\frac{1}{4 \sigma \varepsilon \mathrm{T}_{\mathrm{m}}^{3}} \\
& \mathrm{r}_{\mathrm{c}}=\frac{\mathrm{l}_{\mathrm{c}}-\mathrm{l}_{\mathrm{cw}}}{\rho \mathrm{C}_{\mathrm{p}}}\left(\frac{\left(\mathrm{T}_{\mathrm{s}}-\mathrm{T}_{\mathrm{c}}\right)^{0.53}}{14.5 \times 10^{4}}+\frac{k_{a}}{\rho C_{p}}+\frac{16 \sigma \mathrm{T}_{\text {mid }}^{3}}{\rho C_{p}\left(3 p_{\mathrm{c}}\right)}\right)^{-1}
\end{aligned}
$$

where $d$ is the characteristic dimension of the animal $(\mathrm{m}), \mathrm{k}_{\mathrm{a}}$ is the thermal conductivity of air $\left(\mathrm{W} \mathrm{m}^{-1} \mathrm{~K}^{-1}\right)$, and $\mathrm{N}_{\mathrm{u}}$ is the Nusselt number. The Nusselt number can be obtained from $\mathrm{N}_{\mathrm{u}}=\mathrm{B} \mathrm{Gr}^{\mathrm{m}}$ for free and natural convection flows. Monteith and Unsworth (Monteith \& Unsworth, 2008) assigned B $=0.48$ and $\mathrm{m}=0.25$. The Grashof number was calculated as $\mathrm{Gr}=\mathrm{gTd}^{3} / v^{2} \mathrm{~T} . v$ is the kinematic viscosity of air $\left(\mathrm{m}^{2} \mathrm{~s}^{-1}\right), \mathrm{g}$ is the gravitational acceleration $\left(\mathrm{m} \mathrm{s}^{-2}\right), \Delta \mathrm{T}$ is the mean difference between the surface temperature and bulk temperature $\left({ }^{\circ} \mathrm{C}\right)$, and $\overline{\mathrm{T}}$ is the average absolute temperature of the surface temperature and bulk temperature $(\mathrm{K}) . \mathrm{T}_{\mathrm{m}}$ is the average temperature $(\mathrm{K})$ between the radiant temperature of the enclosure $\left(T_{r}\right)$ and the hair-coat temperature $\left(T_{c}\right), \sigma$ is the Stefan-Boltzmann constant $\left(5.670373 \times 10^{-8} \mathrm{~W} \mathrm{~m}^{-2} \mathrm{~K}^{-4}\right)$, and $\varepsilon$ is the emissivity. For the indoor animals, $\mathrm{T}_{\mathrm{r}}$ can be assumed to be the average temperature of the walls and floor (Turnpenny et al., 2000b). $l_{c}$ is the coat depth $(\mathrm{m}), \mathrm{l}_{\mathrm{cw}}$ is the depth of wind penetration in the hair-coat $(m), \rho C_{p}$ is the volumetric specific heat of air (approximately $1220 \mathrm{~J} \mathrm{~m}^{-3} \mathrm{~K}^{-1}$ at $\left.20{ }^{\circ} \mathrm{C}\right), \mathrm{p}_{\mathrm{c}}$ is the coat penetration parameter $\left(\mathrm{m}^{-1}\right)$ that is the "projected area of hair on the plane of the skin per unit skin area, for a unit depth of coat," which are approximately $500 \mathrm{~m}^{-1}$ for sheep and $1800 \mathrm{~m}^{-1}$ for cattle, and $\mathrm{T}_{\text {mid }}$ is the average temperature between the skin and the outer surface of hair-coat $(\mathrm{K})$.

On the assumption that steady heat flows from and to each region of the body without any heat storage in any layer, two equations can be derived. Because two unknown variables, $T_{s}$ and $T_{c}$, exist, equations (A-1), (A-5), and (A-6) are solved by an iterative method to generate successive approximations to the solutions for $T_{s}$ and $T_{c}$.

$\mathrm{Q}_{\mathrm{t}}=\mathrm{R}\left(\mathrm{Q}_{\mathrm{c}}+\mathrm{E}_{\mathrm{r}}\right)+(1-\mathrm{R}) \mathrm{Q}_{\mathrm{flr}}$

$\mathrm{Q}_{\mathrm{c}}=\mathrm{Q}_{\mathrm{a}}+\mathrm{Q}_{\mathrm{r}}$

where $\mathrm{R}$ is the proportion of the animal's trunk exposed to the air, and $E_{r}$ is the latent heat loss from the respiratory tract (W $\mathrm{m}^{-2}$ ).

When the solutions are convergent, the rate of sensible heat flux from the animal to the air is derived as follows:

$\mathrm{S}_{\mathrm{T}}=\frac{\mathrm{A}_{\mathrm{c}} \mathrm{n}_{\mathrm{a}} \mathrm{Q}_{\mathrm{a}}}{\rho \mathrm{C}_{\mathrm{p}} \mathrm{V}_{\mathrm{z}}}$

where $A_{c}$ is the surface area of the animal $\left(\mathrm{m}^{2}\right), \mathrm{n}_{a}$ is the number of animals in the building, and $V_{z}$ is the volume of the animal zone in the building $\left(\mathrm{m}^{3}\right)$ calculated by the product of the floor area and the animal height $\left(H_{a}\right)$.

\section{Appendix B. Heat Source from Plant}

The thermal activity of plants can be described in a single energy balance equation.

$$
\begin{aligned}
\mathrm{R}_{\mathrm{c}}=\left.\frac{\mathrm{dR}(\mathrm{z})}{\mathrm{dz}}\right|_{\mathrm{z}_{\mathrm{c}}}= & 2 \mathrm{LAI}_{\mathrm{v}} \cdot \rho \cdot \mathrm{C}_{\mathrm{p}} \cdot \frac{\mathrm{T}_{\mathrm{l}}-\mathrm{T}_{\mathrm{a}}}{\mathrm{r}_{\mathrm{a}}}+2 \mathrm{LAI}_{\mathrm{v}} \cdot \rho \cdot \lambda \cdot \frac{\mathrm{W}_{\mathrm{l}}-\mathrm{W}_{\mathrm{a}}}{\mathrm{r}_{\mathrm{t}}} \\
& +\mathrm{LAI}_{\mathrm{v}} \cdot \mathrm{t}_{\mathrm{l}} \cdot \rho_{\mathrm{l}} \cdot \mathrm{C}_{\mathrm{pl}} \cdot \frac{\mathrm{dT}}{\mathrm{dt}}+\mathrm{M}
\end{aligned}
$$

where $R_{c}$ is the solar radiation absorbed by the leaf at the 
height of $z_{c}\left(W^{-3}\right), R(z)$ is the solar radiation at height $z$ (W $\left.\mathrm{m}^{-2}\right), L A I_{v}$ is the volumetric leaf area density $\left(\mathrm{m}^{2} \mathrm{~m}^{-3}\right), \rho$ and $\rho_{l}$ are the densities of the air and leaves, respectively $\left(\mathrm{kg} \mathrm{m}^{-3}\right), C_{p}$ and $C_{p l}$ are the specific heats of air and leaves, respectively $(J$ $\left.\mathrm{kg}^{-1} \mathrm{~K}^{-1}\right), \lambda$ is the latent heat of water evaporation $\left(2500000 \mathrm{~J} \mathrm{~kg}^{-1}\right), \mathrm{T}_{l}$ and $\mathrm{T}_{a}$ are the temperatures of leaf and air, respectively $(\mathrm{K}), w_{l}$ and $w_{a}$ are the humidities of leaf and air, respectively (mass fraction: mass of water/mass of air), $r_{a}$ is the aerodynamic resistance of leaf $\left(\mathrm{s} \mathrm{m}^{-1}\right), r_{t}$ is the total resistances on both sides of the leaf $\left(\mathrm{s} \mathrm{m}^{-1}\right), t_{l}$ is the thickness of the leaf $(\mathrm{m})$, and $\mathrm{M}$ is the net rate of heat storage in metabolic reactions, e.g., photosynthesis or respiration.

The primary source is the indoor solar radiation that is a function of the height above the floor. The absorbed solar energy in the leaves is exchanged with the nearby air in forms of sensible and latent heat.

$\mathrm{R}(\mathrm{z})=\mathrm{R}_{\text {net }} \cdot \exp \left(-\mathrm{K}_{\mathrm{c}} \cdot \mathrm{LAI} \cdot \frac{\mathrm{h}-\mathrm{z}}{\mathrm{h}}\right)$

where $R_{\text {net }}$ is the net solar radiation at the top of the crop, $K_{c}$ is the extinction coefficient, and $h$ is the crop height (m).

The first and second terms in the right side of equation (B1) represent the sensible and latent heat exchanges at the leaves, respectively. These exchanges occur through the leaves' stomata. Because tomato leaves contain stomata on both sides, the ratio of the upper stomatal resistance face of the leaf by that underneath was introduced. The ratio (AA) depends primarily on the stomatal aperture and on the solar radiation at the crop level; and Boulard et al. (2004) suggested 2.7 and $1 / 17.5$ for constants $a$ and $b$, respectively.

$\mathrm{AA}=\ln \left(\mathrm{a}+\mathrm{b} \cdot \mathrm{R}_{\mathrm{net}}\right)$

The total resistance of the leaf is calculated as follows:

$r_{t}=\left(\frac{1}{r_{a}+r_{s}}+\frac{1}{r_{a}+A A r_{s}}\right)^{-1}$

where $r_{\mathrm{s}}$ is the stomatal resistance of the leaf $\left(\mathrm{s} \mathrm{m}^{-1}\right)$.

The aerodynamic resistance on the leaf is affected by the leaf boundary layer and depends on the shape of the leaf and air velocity near the leaf.

$r_{a}=305 \sqrt{\frac{L}{v+v_{0}}}$

where $L$ is the characteristic length of the leaf $(\mathrm{m})$. The velocity induced by the buoyancy effect $\left(v_{0}\right)$ depends on the shape and surface temperature of the leaf and is calculated as

$\mathrm{v}_{0}=\frac{\sqrt{\mathrm{g} \cdot\left|\mathrm{T}_{1}-\mathrm{T}_{\mathrm{a}}\right| \cdot \mathrm{L} \cdot 0.5}}{\sqrt{\mathrm{T}_{1}}}$

The aerodynamic resistance for water vapour exchange is known to be 0.93 times that for heat exchange (Goudriaan \& Van Laar, 1994).

The stomatal resistance occurs when water vapour or carbon dioxides are diffused through the stomata. It generally ranges from 50 to $10,000 \mathrm{~s} \mathrm{~m}^{-1}$, and depends on the crops. Shaer and Van Bavel (1987) indicated that the stomatal resistance can be $20 \mathrm{~s} \mathrm{~m}^{-1}$ for a tomato crop. Demrati et al. (2007) suggested that the stomatal resistance was primarily calculated by a combination of solar radiation intensity $\left(\mathrm{f}_{1}\left(\mathrm{x}_{1}\right)\right)$ at the crop level and air saturation deficit $\left(\mathrm{f}_{2}\left(\mathrm{x}_{2}\right)\right)$, or by a combination of solar radiation intensity and leaf temperature:

$\mathrm{r}_{\mathrm{s}}=\mathrm{r}_{\mathrm{s}, \min } \cdot \mathrm{f}_{1}\left(\mathrm{x}_{1}\right) \cdot \mathrm{f}_{2}\left(\mathrm{x}_{2}\right)$

$\mathrm{f}_{\mathrm{j}}\left(\mathrm{x}_{\mathrm{j}}\right)=1+\mathrm{a}_{0}\left[\exp \left(\mathrm{a}_{1}\left(\mathrm{x}_{\mathrm{j}}-\mathrm{a}_{2}\right)\right)\right]^{\mathrm{n}}$

Table B1 - Climatic factors for aerodynamic resistance of tomato crop (Boulard \& Wang, 2002; Demrati et al., 2007).

\begin{tabular}{lllll}
$\mathrm{x}_{\mathrm{j}}$ & $\mathrm{a}_{0}$ & $\mathrm{a}_{1}$ & \multicolumn{1}{c}{$\mathrm{a}_{2}$} & $\mathrm{n}$ \\
\hline $\mathrm{R}(\mathrm{z})$ & 1 & 0.05 & 49 & -1 \\
$\mathrm{D}_{\text {sat }}$ & 0.11 & 0.34 & $\mathrm{Dmax}$ & 1 \\
\hline
\end{tabular}

$D_{\text {sat }}$ and $D_{\max }$ are the saturation deficit of air and the maximum saturation deficit, respectively.

The empirical equation was used to estimate the saturation pressure $(\mathrm{Pa})$ of air.

$P_{\text {sat }}=610.78 \times \exp \left(\frac{17.25 \times\left(\mathrm{T}_{\mathrm{a}}-273.15\right)}{237.8+\left(\mathrm{T}_{\mathrm{a}}-273.15\right)}\right)$

The third and fourth terms in the right hand of equation (B1) are for heat storages of leaves in terms of physical temperature change and metabolic reactions, respectively. The specific heat of the leaves varies from 3500 to $4000 \mathrm{~J} \mathrm{~kg}^{-1} \mathrm{~K}^{-1}$, but the heat capacity of the leaves is frequently ignored because the energy storage is dominated by the large mass of the soil. The energy use in metabolism tends to be minuscule, and is typically only $1.5-3 \%$ of the incoming radiation is used for photosynthesis (Jones \& Rotenberg, 2001).

Assuming that all other parameters are provided, the unknown variables are the temperature and humidity of the leaf. To solve the two unknown variables, an additional equation apart from the energy balance equation is derived from the relationship between the temperature and humidity of the leaf by assuming that the inside of the leaf is saturated.

$\mathrm{P}_{1, \text { sat }}=610.78 \times \exp \left(\frac{17.25 \times\left(\mathrm{T}_{1}-273.15\right)}{237.8+\left(\mathrm{T}_{1}-273.15\right)}\right)$

Two unknown variables and two equations are solved by an iterative method to obtain a convergent solution. From the solution, the source term for the rate of sensible heat generation owing to plants is derived as

$\mathrm{S}_{\mathrm{T}}=2 \mathrm{LAI}_{\mathrm{v}} \frac{\mathrm{T}_{\mathrm{l}}-\mathrm{T}_{\mathrm{a}}}{\mathrm{r}_{\mathrm{a}}}$

\section{Appendix C. Supplementary data}

Supplementary data to this article can be found online at https://doi.org/10.1016/j.biosystemseng.2020.03.005.

\section{R E F E R E N C E S}

Ai, Z., \& Mak, C. (2014). Modeling of coupled urban wind flow and indoor air flow on a high-density near-wall mesh: Sensitivity 
analyses and case study for single-sided ventilation. Environmental Modelling \& Software, 60, 57-68.

Behera, S., Sharma, M., Aneja, V., \& Balasubramanian, R. (2013). Ammonia in the atmosphere: A review on emission sources, atmospheric chemistry and deposition on terrestrial bodies. Environmental Science and Pollution Research, 20(11), 8092-8131.

Bjerg, B., Cascone, G., Lee, I., Bartzanas, T., Norton, T., Hong, S., \& Zhang, G. (2013). Modelling of ammonia emissions from naturally ventilated livestock buildings. Part 3: CFD modelling. Biosystems Engineering, 116(3), 259-275.

Bjerg, B., Norton, T., Banhazi, T., Zhang, G., Bartzanas, T., Liberati, P., \& Marucci, A. (2013). Modelling of ammonia emissions from naturally ventilated livestock buildings. Part 1: Ammonia release modelling. Biosystems Engineering, 116(3), 232-245.

Boulard, T., Fatnassi, H., Roy, J., Lagier, J., Fargues, J., Smits, N., \& Jeannequin, B. (2004). Effect of greenhouse ventilation on humidity of inside air and in leaf boundary-layer. Agricultural and Forest Meteorology, 125(3-4), 225-239.

Boulard, T., \& Wang, S. (2002). Experimental and numerical studies on the heterogeneity of crop transpiration in a plastic tunnel. Computers and Electronics in Agricuclture, 34(1-3), 173-190.

Bournet, P., \& Boulard, T. (2010). Effect of ventilator configuration on the distributed climate of greenhouses: A review of experimental and CFD studies. Computers and Electronics in Agriculture, 74(2), 195-217.

Buggenhout, S., Ozcan, S., Vranken, E., Van Malcot, W., \& Berckmans, D. (2007). Acoustical ventilation rate sensor concept for naturally ventilated buildings. ASHRAE Transactions, 113(2), 192-200.

Burton, T., Jenkins, N., Sharpe, D., \& Bossanyi, E. (2011). Wind energy handbook. Chichester, United Kingdom: John Wiley and Sons Ltd.

Burton, T., Sharpe, D., Jenkins, N., \& Bossanyi, E. (2001). Wind energy handbook. Chichester: John Wiley \& Sons.

Demrati, H., Boulard, T., Fatnassi, H., Bekkaoui, A., Majdoubi, H., Elattir, H., et al. (2007). Microclimate and transpiration of a greenhouse banana crop. Biosystems Engineering, 98(1), 66-78.

EuropeanCommission. (2008). Green paper on agricultural product quality: Product standards, farming, requirements and quality schemes COM (Vol. 641).

Goudriaan, J., \& Van Laar, H. (1994). Modelling potential crop growth processes: Textbook with exercises. Netherlands: Kluwer Academic Publishers.

Hong, S. (2008). Analytical comparison on ventilation efficiencies of naturally-ventilated multi-spant greenhouse and development of crop model using CFD technology. South Korea: M.S., Seoul National University.

Hong, S., Exadaktylos, V., \& Berckmans, D. (2014). Automating CFD to calculate ventilation rate of a naturally ventilate building. In Paper presented at the the 18th world. Beijing, China: Congress of CIGR.

Hong, S., Exadaktylos, V., Lee, I., Amon, T., Youssef, A., Norton, T., et al. (2017). Validation of an open source CFD code to simulate natural ventilation for agricultural buildings. Computers and Electronics in Agricuclture, 138, 80-91.

Hong, S., Lee, I., Hwang, H., Seo, I., Bitog, J., Kwon, K., \& Chung, S. (2011). CFD modelling of livestock odour dispersion over complex terrain, part II: Dispersion modelling. Biosystems Engineering, 108(3), 265-279. https://doi.org/10.1016/ j.biosystemseng.2010.12.008.

Hong, S., Lee, I., Hwang, H., Seo, I., Bitog, J., Kwon, K., \& Ko, H. (2011). CFD modelling of livestock odour dispersion over complex terrain, part I: Topographical modelling. Biosystems Engineering, 108(3), 253-264. https://doi.org/10.1016/

j.biosystemseng.2010.12.009.
Hong, S., Lee, I., Hwang, H., Seo, I., Bitog, J., Yoo, J., \& Yoon, N. (2008). Numerical simulation of ventilation efficiencies of naturally ventilated multi-span greenhouses in Korea. Transactions of the ASABE, 51(4), 1417-1432.

Ivchenko, A. (2011). Incorporation of openfoam software into computational fluid dynamics process in volvo technology. Sweden: M.S., Halmstad University.

Jones, H., \& Rotenberg, E. (2001). Energy, radiation and temperature regulation in plants. Encyclopedia of Life Science, 1-8. Wiley, New York.

Kwon, K., Lee, I., Han, H., Shin, C., Hwang, H., Hong, S., \& Han, C. (2011). Analysing ventilation efficiency in a test chamber using age-of-air concept and CFD technology. Biosystems Engineering, 110(4), 421-433.

Lee, I. (1998). Short fluid dynamic simulation of A naturally ventilated multi-span greeshouse.

Lee, I., Bitog, J., Hong, S., Seo, I., Kwon, K., Bartzanas, T., et al. (2013). The past, present and future of CFD for agroenvironmental applications. Computers and Electronics in Agriculture, 93, 168-183.

Lee, S., Lee, I., \& Kim, R. (2018). Evaluation of wind-driven natural ventilation of single-span greenhouses built on reclaimed coastal land. Biosystems Engineering, 171, 120-142.

Lee, I., Sase, S., Okushima, L., Ikeguchi, A., \& Park, W. (2002). The accuracy of computational simulation for naturally ventilated multi-span greenhouse. In Paper presented at the 2002 ASAE annual meeting.

Lee, I., \& Short, T. (2000). Two-dimensional numerical simulation of natural ventilation in a multi-span greenhouse. Transactions of the ASAE, 43(3), 757.

Lee, I., \& Short, T. (2001). Verification of computational fluid dynamic temperature simulations in a full-scale naturally ventilated greenhouse. Transactions of the ASAE, 44(1), 119.

Lee, I., Short, T., Sase, S., \& Lee, S. (2000). Evaluation of computational fluid dynamics for analysis of aerodynamics in naturally ventilated multi-span greenhouse. Agricultural and Biosystems Engineering, 1(2), 73-80.

Lee, I., Short, T., Sase, S., Okushima, L., \& Qiu, G. (2000). Evaluation of structural characteristics of naturally ventilated multi-span greenhouses using computer simulation. Japan Agricultural Research Quarterly, 34(4), 247-256.

Monteith, J., \& Unsworth, M. (2008). Principles of environmental physics. London: Edward Arnold.

Norton, T., Grant, J., Fallon, R., \& Sun, D. (2010). Improving the representation of thermal boundary conditions of livestock during CFD modelling of the indoor environment. Computers and Electronics in Agriculture, 73(1), 17-36.

Norton, T., Sun, D., Grant, J., Fallon, R., \& Dodd, V. (2007). Applications of computational fluid dynamics (CFD) in the modelling and design of ventilation systems in the agricultural industry: A review. Bioresource Technology, 98(12), 2386-2414.

Ozcan, S., \& Berckmans, D. (2010). A critical evaluation of the accuracy of tracer gas measurements in ventilated spaces. In Paper presented at the proceedings of the CIGR XVIIth world congress (CSBE100467).

Park, S., Lee, I., \& Hong, S. (2014). New development of a straightforward method of estimating age-of-air using CFD. ISHS Acta Horticulturae, 1037, 963-969.

Samer, M., Loebsin, C., Fiedler, M., Ammon, C., Berg, W., Sanftleben, P., et al. (2011). Heat balance and tracer gas technique for airflow rates measurement and gaseous emissions quantification in naturally ventilated livestock buildings. Energy and Buildings, 43(12), 3718-3728.

Sase, S., Kacira, M., Boulard, T., \& Okushima, L. (2012). Wind tunnel measurement of aerodynamic properties of a tomato canopy. Transactions of the ASABE, 55(5), 1921-1927.

Shaer, Y., \& Van Bavel, C. (1987). Relative role of stomatal and aerodynamic resistances in transpiration of a tomato crop in a 
CO2-enriched greenhouse. Agricultural and Forest Meteorology, $41(1-2), 77-85$.

Skjøth, C., \& Geels, C. (2013). The effect of climate and climate change on ammonia emissions in Europe. Atmospheric Chemistry and Physics, 13, 117-128.

Takai, H., Nimmermark, S., Banhazi, T., Norton, T., Jacobson, L., Calvet, S., \& Berckmans, D. (2013). Airborne pollutant emissions from naturally ventilated buildings: Proposed research directions. Biosystems Engineering, 116(3), 214-220.

Tominaga, Y., Mochida, A., Yoshie, R., Kataoka, H., Nozu, T., Yoshikawa, M., et al. (2008). AIJ guidelines for practical applications of CFD to pedestrian wind environment around buildings. Journal of Wind Engineering and Industrial Aerodynamics, 96(10-11), 1749-1761.

Turnpenny, J. R., McArthur, A., Clark, J., \& Wathes, C. (2000). Thermal balance of livestock: 1. A parsimonious model. Agricultural and Forest Meteorology, 101(1), 15-27.
Turnpenny, J. R., Wathes, C. M., Clark, J. A., \& McArthur, A. J. (2000). Thermal balance of livestock 2. Applications of a parsimonious model. Agricultural and Forest Meteorology, 101(1), 29-52. https://doi.org/10.1016/s0168-1923(99)00157-4.

Wakes, S., Maegli, T., Dickinson, K., \& Hilton, M. (2010). Numerical modelling of wind flow over a complex topography. Environmental Modelling and Software, 25(2), 237-247. https:// doi.org/10.1016/j.envsoft.2009.08.003.

Wang, S. (1998). Measurement and modelling of natural ventilation in a large Venlo-type greenhouse. Ph.D. Gembloux, Belgium: Faculte Universitaire des Sciences Agronomiques de Gembloux

Wang, S., \& Boulard, T. (2000). Predicting the microclimate in a naturally ventilated plastic house in a mediterranean climate. Journal of Agricultural Engineering Research, 75(1), 27-38. https:// doi.org/10.1006/jaer.1999.0482.

Wilson, J. (1985). Numerical studies of flow through a windbreak. Journal of Wind Engineering and Industrial Aerodynamics, 21(2), 119-154. https://doi.org/10.1016/0167-6105(85)90001-7. 